\title{
Relationship of Cough Strength to Respiratory Function, Physical Performance, and Physical Activity in Older Adults
}

\author{
Hideo Kaneko, Akari Suzuki, and Jun Horie
}

\begin{abstract}
BACKGROUND: Age- and lifestyle-related changes in respiratory and physical function affect cough strength. However, in older adults, the main factors that relate to cough strength remain unclear. This study was a preliminary investigation of factors that contribute to cough strength and the relationships between cough strength and respiratory function, physical performance, physical activity, and sedentary behavior in community-dwelling older adults. METHODS: By using accelerometers and other tools, we assessed cough peak flow (CPF), FVC, maximum inspiratory pressure $\left(\mathbf{P}_{\text {Imax }}\right)$, maximum expiratory pressure $\left(\mathbf{P}_{\text {Emax }}\right)$, chest and abdominal wall mobility (breathing movement scale), physical performance (Timed Up and Go test and 30-s chair stand test), physical activity (steps, and locomotive and non-locomotive moderate-to-vigorous physical activity), and sedentary behavior (sedentary time) in 65 community-dwelling older adults ( 25 males and 40 females) without air-flow limitation. RESULTS: Twenty-six percent of the subjects (17/65) had reduced CPF $(<240 \mathrm{~L} / \mathrm{min})$. The subjects with reduced $\mathrm{CPF}$ had significantly lower $\mathrm{FVC}, \mathrm{P}_{\text {Imax }}$, $\mathbf{P}_{\text {Emax }}$, chest and abdominal wall mobility, physical performance, and locomotive moderate-tovigorous physical activity compared with those with non-reduced CPF. Significant correlations between CPF and variables of respiratory function (FVC, $\mathbf{P}_{\text {Imax }}, \mathbf{P}_{\text {Emax }}$, and breathing movement scale) and physical performance were weak to moderate. FVC and $P_{I m a x}$ were independently associated with CPF during the multiple regression analysis adjusted for sex, age, and height. The receiver operating characteristic analysis showed that $F V C$ and $P_{\text {Imax }}$ had fair-to-good sensitivity for detecting reduced CPF. CONCLUSIONS: Analysis of our results indicated that FVC and $\mathbf{P}_{\text {Imax }}$ were related to CPF and provided preliminary evidence that supported strategies for preserving and improving cough strength in community-dwelling older adults. Key words: cough; pulmonary function; physical performance; physical activity; sedentary behavior; older adults. [Respir Care 2019;64(7):828-834. (C) 2019 Daedalus Enterprises]
\end{abstract}

\section{Introduction}

Cough is an important defensive mechanism to protect and clear the airways. ${ }^{1}$ Cough occurs as a consequence of aspiration, inhaled material, accumulated secretions, and inflammation. However, in older adults, age-related cough

\footnotetext{
Drs Kaneko and Suzuki are affiliated with the Department of Physical Therapy, School of Health Sciences at Fukuoka, International University of Health and Welfare, Okawa-shi, Fukuoka, Japan. Dr Horie is affiliated with the Department of Physical Therapy, School of Health Sciences, Kyoto Tachibana University, Kyoto-shi, Kyoto, Japan.
}

The study was performed at International University of Health and Welfare, Fukuoka, Japan.

The authors have disclosed no conflicts of interest. reflex changes can increase the risk of lung infection and aspiration pneumonia. Pneumonia is the third leading cause of death in Japan (http://www.mhlw.go.jp/english/ database/db-hh/1-2.html. Accessed June 27, 2018). In older adults, most instances of pneumonia are related to aspiration. Impaired cough can contribute to the development of aspiration pneumonia in older adults. ${ }^{2}$ Cough strength, fre-

\footnotetext{
Correspondence: Hideo Kaneko, Department of Physical Therapy, School of Health Sciences at Fukuoka, International University of Health and Welfare, 137-1 Enokizu, Okawa-shi, Fukuoka 831-8501, Japan. E-mail: hkaneko@iuhw.ac.jp.
}

DOI: $10.4187 /$ respcare.06490 
quently expressed as $\mathrm{CPF}$, is a good predictor of pulmonary complications in patients with dysphagia. ${ }^{3}$

Effective cough depends on sufficient respiratory muscle strength to increase lung volume and promote high expiratory flow. ${ }^{1}$ Respiratory muscle strength and lung volume decline with age, and respiratory muscle weakness and reduced chest and abdominal wall mobility limit lung volumes. ${ }^{4,5}$ Reduced lung volume restricts the volume of air that can be inhaled, which reduces positive intrathoracic pressure, which, in turn, diminishes CPF.,6 In addition to age-related effects, poor physical performance and physical inactivity have an adverse impact on respiratory muscle strength ${ }^{7-9}$ and lung volumes ${ }^{10,11}$ in older adults. One study showed that active older adults, classified by self-report questionnaires, had higher CPF and respiratory muscle strength. ${ }^{12}$ Thus, physical performance, physical activity, and sedentary behavior potentially affect CPF in older adults. However, in older adults, the relationship between CPF and respiratory function, physical performance, physical activity, and sedentary behavior necessitates further investigation.

Physical activity and sedentary behavior are typically assessed by using self-report methods. However, self-report questionnaires are subject to recall bias, particularly among older adults who tend to overestimate their physical activity compared with objective measures (eg, accelerometers). ${ }^{13}$ Objective measures of physical activity and sedentary behavior are more accurate and, therefore, more meaningful contributors to examinations of older adults. Thus, objective assessments of physical activity and sedentary behavior may help identify factors that affect CPF and formulate strategies for mitigating the risk of pulmonary complications in older adults. Therefore, this was a preliminary investigation of factors that contribute to $\mathrm{CPF}$ and the relationships between $\mathrm{CPF}$ and respiratory function, physical performance, physical activity, and sedentary behavior in older adults.

\section{Methods}

\section{Participants}

Sixty-nine community-dwelling, ambulatory older adults ages $\geq 65$ y from community-based organization in Okawa, Japan, from May to July 2017 participated in this study. We excluded individuals with lung disease or neurologic diseases, air-flow limitation, body mass index $>30 \mathrm{~kg} / \mathrm{m}^{2}$, and cognitive disorders that impeded direction-following abilities. The remaining 65 individuals ( 25 males and 40 females) with at least 4 valid days of accelerometer data ( $\geq 10 \mathrm{~h}$ of wear time per day) were included in this study. The sample size calculation of 57 participants was based on our previous study, which showed a large effect size, ${ }^{14}$ when considering 10 variables, power of $80 \%, \alpha=0.05$,

\section{QUICK LOOK}

\section{Current knowledge}

Impaired cough can contribute to the development of aspiration pneumonia in older adults. Cough strength, frequently expressed as CPF, is a good predictor of pulmonary complications. Studies have shown associations between CPF and age- and lifestyle-related changes in respiratory and physical functions.

\section{What this paper contributes to our knowledge}

In ambulatory community-dwelling older adults, FVC and maximum inspiratory pressure were independently associated with CPF and had fair-to-good sensitivity for detecting reduced $\mathrm{CPF}(<240 \mathrm{~L} / \mathrm{min})$. Our findings indicate that lung volume and maximum inspiratory strength may assist efforts to establish a strategy for preserving and improving cough strength in older adults.

and $\mathrm{f}^{2}=0.35$ for the multiple regression analysis. The effect size $\mathrm{f}^{2}$ for multiple regressions was defined as the following: $\mathrm{f}^{2}=\mathrm{R}^{2} /\left(1-\mathrm{R}^{2}\right)$, where $\mathrm{R}^{2}$ was the squared multiple correlation coefficient. This study was approved by the ethics committee of the International University of Health and Welfare (17-Ifh-02), and all the participants provided their written informed consent.

\section{Cough Strength}

Cough strength, as estimated by CPF, was assessed by using an oronasal mask connected to a portable peak flow meter (Access Peak Flow Meter, Philips Respironics, Murrysville, Pennsylvania). The subjects were seated and instructed to perform a volitional, maximum effort cough after inspiration to total lung capacity. CPF was measured 3 times with the subject in the sitting position, and the highest value was recorded. A CPF of $<240 \mathrm{~L} / \mathrm{min}$ was regarded as reduced because a previous study found that this flow was the cutoff value (CPF cutoff value of $242 \mathrm{~L} /$ min) for identifying patients with dysphagia who were at risk for aspiration pneumonia. ${ }^{3}$

\section{Spirometry}

FVC and $\mathrm{FEV}_{1} / \mathrm{FVC}$ were measured by using a spirometer (Spirobank, Medical International Research, Rome, Italy). All measurements were performed according to the American Thoracic Society and European Respiratory Society guidelines. ${ }^{15}$ The diagnostic spirometry threshold for the lower limit of normal is the fifth percentile of distribution based on the reference equations derived by using 
the Lamda- $\mu$-Sigma method. ${ }^{16}$ Air-flow limitation was defined as $\mathrm{FEV}_{1} / \mathrm{FVC}$ less than the lower limit of normal. $\mathrm{FVC}$ and $\mathrm{FEV}_{1} / \mathrm{FVC}$ were measured 3 times with the subject in the sitting position, and the highest value was recorded. FVC percentage of predicted was calculated by using predicted reference values.

\section{Respiratory Muscle Strength}

Respiratory muscle strength was assessed by measuring the maximum inspiratory pressure $\left(\mathrm{P}_{\mathrm{Imax}}\right)$ and the maximum expiratory pressure $\left(\mathrm{P}_{\mathrm{Emax}}\right)$ by using a pressure manometer (MicroRPM, CareFusion, Hoechberg, Germany). $\mathrm{P}_{\text {Imax }}$ and $\mathrm{P}_{\text {Emax }}$ were measured with the subject in the sitting position and starting from residual volume and total lung capacity, respectively, according to the American Thoracic Society and European Respiratory Society guidelines. ${ }^{17}$ Measurements were repeated at least 3 times, and the highest value was recorded.

\section{Chest and Abdominal Wall Mobility}

Chest and abdominal wall mobility was assessed by using the breathing movement scale for deep breathing. ${ }^{18}$ The breathing movement scale evaluates chest and abdominal wall movements during deep breathing, on a scale of $0-8$. On the breathing movement scale, reduced mobility is indicated by less than the lower limits of deep breathing movements in healthy adults (scale value of $<4$ ). Scale values were measured by using a custom-made breathing movement measuring device (Pacific Medico, Tokyo, Japan) according to a previous study. ${ }^{19}$ The subjects were placed in the supine position. Breathing movements, which ranged from the end of maximum expiration (residual volume) to maximum inspiration (total lung capacity), were measured at 5 observation points in 3 regions: right and left sides of the third rib (upper chest) and eighth rib (lower chest), along the vertical line through the medial one third of the clavicle, and the mid point between the xiphoid process and umbilicus (abdomen) along the vertical line through the umbilicus. The measurements were performed at least twice, and we recorded the maximum value in each region. For the upper and lower chest regions, we recorded the averages on the right and left sides. In addition, we calculated the total scale value of the 3 regions (0-24).

\section{Physical Performance}

Physical performance was estimated by the Timed Up and Go test ${ }^{19}$ and the 30 -s chair stand test. ${ }^{20}$ The Timed Up and Go test is a screening tool that evaluates gait and balance, and is used to predict fall risk. Timed Up and Go time was measured as the time taken, in seconds, to stand up from an armless chair, walk at maximum speed for $3 \mathrm{~m}$, turn around a cone, walk back, and sit down in the chair. The fastest time was recorded for 2 trials. The 30-s chair stand test assesses lower body functional performance. The subjects were asked to perform as many chair stands as possible in $30 \mathrm{~s}$, after a practice trial, to check proper form. Full stands that were completed in $30 \mathrm{~s}$, with arms folded across the chest, were counted.

\section{Physical Activity and Sedentary Behavior}

Physical activity and sedentary behavior were measured by using a tri-axial accelerometer (Active style Pro HJA750C, Omron Healthcare, Kyoto, Japan). The accelerometer counted steps and recorded physical activity in metabolic equivalents for 10-s epochs. Each subject was instructed to wear the accelerometer on the left or right side of his or her waist for at least 7 consecutive days while awake (except during bathing and showering). Nonwear time was defined as an interval of at least 60 consecutive minutes of zero physical activity level. The physical activity data processing algorithm classified activities into either locomotive or non-locomotive. ${ }^{21} \mathrm{We}$ calculated locomotive and non-locomotive moderate-to-vigorous physical activity (metabolic equivalents, h/d). Sedentary time $(\mathrm{h} / \mathrm{d})$ was defined as the time of $\leq 1.5$ metabolic equivalents of non-locomotive physical activity. We calculated percentage sedentary time as a proportion of total sedentary time to total wear time.

\section{Statistical Analysis}

Data were summarized as mean $\pm \mathrm{SD}$ for continuous variables, median (range) for ordinal variables, and numbers for categorical variables. Normal distributions of variables were verified by using the Shapiro-Wilk test. Differences between the subjects with reduced CPF and non-reduced CPF were assessed by using unpaired $t$ tests or MannWhitney tests. Categorical variables were compared by using the Fisher exact test. Respiratory function, physical performance, physical activity, and sedentary behavior variables that were significantly associated with CPF, as determined by the Pearson correlation coefficient, were selected and subjected to multiple linear regression analysis to identify significant independent factors that related to $\mathrm{CPF}$, after adjusting for sex, age, and height, as possible confounders.

Residual analyses were conducted to confirm the normality, linearity, and equal variance of the regression model. The receiver operating characteristic curve identified a cutoff value for the independent variables that discriminated between reduced $\mathrm{CPF}$ and non-reduced CPF. Cutoff values were calculated to optimize the sensitivity and specificity. The area under the curve was calculated to assess 
Table 1. Subject Characteristics

\begin{tabular}{|c|c|c|c|c|}
\hline \multirow{2}{*}{ Variables } & \multirow{2}{*}{ Total $(N=65)$} & \multicolumn{2}{|c|}{$\mathrm{CPF}$} & \multirow{2}{*}{$P$} \\
\hline & & Reduced $(n=17)$ & Non-Reduced $(n=48)$ & \\
\hline Age, y & $78 \pm 6$ & $81 \pm 6$ & $77 \pm 6$ & .02 \\
\hline Males/females & $25 / 40$ & $2 / 15$ & $23 / 25$ & $.009 *$ \\
\hline Height, mean $\pm \mathrm{SD} m$ & $1.54 \pm 0.08$ & $1.50 \pm 0.09$ & $1.56 \pm 0.07$ & .01 \\
\hline Weight, mean \pm SD kg & $54.4 \pm 9.5$ & $50.4 \pm 9.9$ & $55.9 \pm 9.1$ & .042 \\
\hline $\mathrm{BMI}$, mean $\pm \mathrm{SD} \mathrm{kg} / \mathrm{m}^{2}$ & $22.8 \pm 3.4$ & $22.2 \pm 3.4$ & $22.9 \pm 3.4$ & .45 \\
\hline $\mathrm{CPF}$, mean $\pm \mathrm{SD} \mathrm{L} / \mathrm{min}$ & $314 \pm 113$ & $196 \pm 33$ & $356 \pm 100$ & $<.001 \dagger$ \\
\hline $\mathrm{FVC}$, mean $\pm \mathrm{SD} \mathrm{L}$ & $2.37 \pm 0.67$ & $1.84 \pm 0.56$ & $2.55 \pm 0.61$ & $<.001 \dagger$ \\
\hline $\mathrm{FVC}$, mean $\pm \mathrm{SD} \%$ predicted & $90.7 \pm 17.2$ & $80.9 \pm 18.2$ & $94.2 \pm 15.6$ & .005 \\
\hline $\mathrm{FEV}_{1} / \mathrm{FVC}$, mean $\pm \mathrm{SD} \%$ & $77.1 \pm 7.9$ & $79.8 \pm 8.6$ & $76.2 \pm 7.5$ & .11 \\
\hline 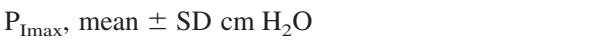 & $52.3 \pm 26.6$ & $40.0 \pm 20.5$ & $56.7 \pm 27.3$ & $.01 \dagger$ \\
\hline $\mathrm{P}_{\text {Emax }}$, mean $\pm \mathrm{SD} \mathrm{cm} \mathrm{H}_{2} \mathrm{O}$ & $77.5 \pm 34.0$ & $60.1 \pm 25.8$ & $83.7 \pm 34.6$ & $.006 \dagger$ \\
\hline Breathing movement scale (0-24), median (range) & $13(7-18)$ & $11(8-17)$ & $14(7-18)$ & .045 \\
\hline Timed Up and Go test, mean \pm SD s & $7.3 \pm 2.5$ & $8.7 \pm 4.1$ & $6.7 \pm 1.3$ & .005 \\
\hline 30-s Chair stand test, mean $\pm \mathrm{SD}, n$ & $18.1 \pm 4.5$ & $15.4 \pm 4.2$ & $19.0 \pm 4.2$ & .003 \\
\hline Steps, mean \pm SD steps $/ \mathrm{d}$ & $4,156 \pm 2,828$ & $3,602 \pm 2,365$ & $4,352 \pm 2,972$ & $.37 \dagger$ \\
\hline \multicolumn{5}{|l|}{$\begin{array}{l}\text { Moderate-to-vigorous physical activity, } \\
\text { mean } \pm \text { SD metabolic equivalents } \mathrm{h} / \mathrm{d}\end{array}$} \\
\hline Locomotive & $1.1 \pm 1.6$ & $0.7 \pm 0.7$ & $1.2 \pm 1.8$ & $.042 \dagger$ \\
\hline Non-locomotive & $2.9 \pm 1.8$ & $2.4 \pm 1.4$ & $3.1 \pm 1.8$ & $.21 \dagger$ \\
\hline Sedentary time, mean $\pm \mathrm{SD} h / \mathrm{d}$ & $8.2 \pm 2.0$ & $8.6 \pm 1.9$ & $8.0 \pm 2.0$ & $.56 \dagger$ \\
\hline Sedentary time, mean \pm SD $\% \neq$ & $57.6 \pm 13.7$ & $59.8 \pm 12.7$ & $56.9 \pm 14.1$ & $.81 \dagger$ \\
\hline \multicolumn{5}{|l|}{$\begin{array}{l}\text { * Fisher exact test. } \\
\dagger \text { Mann-Whitney test. } \\
\text { † Proportion of total sedentary time to total wear time. } \\
\text { BMI }=\text { body mass index } \\
\mathrm{P}_{\text {Imax }}=\text { maximum inspiratory pressure } \\
\mathrm{P}_{\text {Emax }}=\text { maximum expiratory pressure }\end{array}$} \\
\hline
\end{tabular}

the abilities of independent variables to distinguish reduced CPF. The area under the curve was compared by using the method of DeLong et al. ${ }^{22}$ All the tests were 2-tailed, and statistical significance was set at $P<.05$. Statistical analyses were performed by using IBM SPSS Statistics for Windows, version 24 (IBM, Armonk, New York) and R version 3.3.2 (R Foundation for Statistical Computing, Vienna, Austria; https://www.r-project.org. Accessed October 27, 2016).

\section{Results}

Subject characteristics are summarized in Table 1. Of the subjects, 26\% (17/65) had reduced CPF. Subjects' average total wear time during waking hours was $14.2 \mathrm{~h} / \mathrm{d}$. The anthropometric data were significantly lower in the subjects with reduced CPF compared with those with nonreduced $\mathrm{CPF}$. All respiratory function and physical performance variables, except $\mathrm{FEV}_{1} / \mathrm{FVC}$, were lower in the subjects with reduced CPF compared with those with nonreduced $\mathrm{CPF}$. There were no significant differences in physical activity and sedentary behavior between the subjects with reduced and the subjects with non-reduced CPF, with the exception of locomotive moderate-to-vigorous physical activity.

The results of the correlation analysis between $\mathrm{CPF}$ and the other variables are shown in Table 2. FVC, $\mathrm{P}_{\text {Imax }}$, $\mathrm{P}_{\text {Emax }}$, breathing movement scale, Timed Up and Go test, and the 30-s chair stand test were significantly correlated with CPF. During multiple linear regression analysis with a dependent variable (CPF) and independent variables (FVC, $\mathrm{P}_{\text {Imax }}, \mathrm{P}_{\text {Emax }}$, breathing movement scale, Timed Up and Go test, and 30-s chair stand test), FVC and $\mathrm{P}_{\text {Imax }}$ were independently associated with CPF (Table 3). Receiver operating characteristic curves showed that the areas under the curve for FVC and $\mathrm{P}_{\text {Imax }}$ were 0.81 , with a cutoff value of $<2.05$ L (sensitivity, 82\%; specificity, 75\%); and 0.70, with a cutoff value of $47 \mathrm{~cm} \mathrm{H}_{2} \mathrm{O}$ (sensitivity, 76\%; specificity, $60 \%$ ), respectively (Table 4 ). There was no significant difference in the area under the curve between FVC and $\mathrm{P}_{\text {Imax }}$.

\section{Discussion}

The major finding of this study was that $\mathrm{FVC}$ and $\mathrm{P}_{\text {Imax }}$ were associated with CPF; also, FVC had good sensitivity for detecting reduced $\mathrm{CPF}$ in ambulatory community- 
Table 2. Correlation Coefficients Between CPF and Variables of Respiratory Function, Physical Activity, and Sedentary Behavior $(N=65)$

\begin{tabular}{lcc}
\hline \hline \multicolumn{1}{c}{ Variable } & Correlation Coefficient $(95 \% \mathrm{CI})$ & $P$ \\
\hline FVC & $0.53(0.33-0.69)$ & $<.001$ \\
$\mathrm{P}_{\text {Imax }}$ & $0.49(0.28-0.66)$ & $<.001$ \\
$\mathrm{P}_{\text {Emax }}$ & $0.41(0.19-0.60)$ & .001 \\
Breathing movement scale & $0.32(0.09-0.53)$ & .02 \\
Timed Up and Go test & $-0.30(-0.50$ to -0.05$)$ & .006 \\
30-s Chair stand test & $0.38(0.16-0.57)$ & .006 \\
Steps & $0.14(-0.11$ to 0.37$)$ & .28 \\
Moderate-to-vigorous & $0.10(-0.15$ to 0.33$)$ & .43 \\
$\quad$ physical activity & $0.18(-0.07$ to 0.40$)$ & .16 \\
$\quad$ Locomotive & $-0.15(-0.39$ to 0.08$)$ & .28 \\
$\quad$ Non-locomotive & $-0.11(-0.34$ to 0.14$)$ & .39 \\
Sedentary time & & \\
Percent sedentary time* & & \\
* Proportion of total sedentary time to total wear time. & \\
$\mathrm{P}_{\text {Imax }}=$ maximum inspiratory pressure & & \\
$\mathrm{P}_{\text {Emax }}=$ maximum expiratory pressure & & \\
\hline
\end{tabular}

Table 3. Results of Multiple Regression Analysis to Detect Independent Variables of CPF With Sex, Age, and Height as Covariates $(N=65)$

\begin{tabular}{lcrrrr}
\hline \hline Model & B (95\% CI) & $\beta$ & $P$ & $\mathrm{R}^{2}$ & $\begin{array}{c}\text { Adjusted } \\
\mathrm{R}^{2}\end{array}$ \\
\hline 1 & & & & 0.34 & 0.30 \\
Sex & $78.9(15.6-142.1)$ & 0.34 & .02 & & \\
Age & $-0.17(-4.73$ to 4.38$)$ & -0.01 & .94 & & \\
Height & $0.41(-3.87$ to 4.95$)$ & 0.02 & .98 & & \\
$\mathrm{P}_{\text {Imax }}$ & $1.51(0.49-2.53)$ & 0.36 & .004 & & \\
2 & & & & 0.40 & 0.35 \\
Sex & $43.6(-25.3$ to 112.4$)$ & 0.19 & .21 & & \\
Age & $1.70(-3.01$ to 6.42$)$ & 0.09 & .47 & & \\
Height & $-1.51(-5.54$ to 2.52$)$ & -0.10 & .46 & & \\
$\mathrm{P}_{\text {Imax }}$ & $1.28(0.27-2.29)$ & 0.30 & .01 & & \\
FVC & $62.9(6.7-119.0)$ & 0.38 & .036 & & \\
& & & & &
\end{tabular}

Sex was coded as $1=$ male and $0=$ female.

$\mathrm{P}_{\mathrm{Imax}}=$ maximum inspiratory pressure

dwelling older adults without air-flow limitation. Previous studies showed that FVC and $\mathrm{P}_{\text {Imax }}$ were associated with CPF in older adults ${ }^{14}$ and subjects with Duchenne muscular dystrophy. ${ }^{23,24}$ These findings were consistent with our results. Conversely, chest and abdominal wall mobility and physical performance variables that were significantly correlated with CPF were not selected as independent predictors. Analysis of these results indicated that lung volume and inspiratory muscle strength may be important factors that relate to $\mathrm{CPF}$ and may assist efforts to establish a strategy for preserving and improving CPF in community-dwelling older adults without air-flow limitation.
The FVC cutoff value of $2.05 \mathrm{~L}$ showed high sensitivity $(82 \%)$ and negative predictive value $(92 \%)$ for predicting reduced $\mathrm{CPF}$. This cutoff value was equivalent to that of a past study in which an FVC $>2.1 \mathrm{~L}$ was associated with an effective cough $(\mathrm{CPF}>270 \mathrm{~L} / \mathrm{min})$ in subjects with Duchenne muscular dystrophy. ${ }^{23}$ Although criteria for effective $\mathrm{CPF}$ differ, these findings indicated that adequate FVC is important for producing effective cough. In the present study, $88 \%$ of the subjects with reduced CPF $(15 / 17)$ were older females and $65 \%$ of those subjects (11/17) showed no restrictive pattern on spirometry. Thus, in this cohort, reduced FVC seemed to relate to age-related declines rather than the presence of respiratory disorders. Analysis of these results indicated that smaller stature, older females with smaller predicted FVCs may be particularly vulnerable to cough strength declines.

In addition, we found no significant difference in the area under the curve between FVC and $\mathrm{P}_{\text {Imax }}$, although the $\mathrm{P}_{\text {Imax }}$ cutoff value of $47 \mathrm{~cm} \mathrm{H}_{2} \mathrm{O}$ showed slightly lower sensitivity (76\%) and negative predictive value (88\%). Previous studies reported that the capacity to generate cough air flow correlated with $\mathrm{P}_{\text {Emax }}$ in patients with neuromuscular disease. ${ }^{25,26}$ In the present study, we observed a significant moderate association between $\mathrm{CPF}$ and $\mathrm{P}_{\text {Emax }}$. However, the expiratory flow reductions caused by muscle weakness were minimal compared with those related to a lack of positive intrathoracic pressure ${ }^{27}$ Furthermore, studies have demonstrated that CPF is independently associated with $\mathrm{P}_{\text {Imax }}$ in older adults, ${ }^{14}$ patients with neuromuscular diseases, ${ }^{24,28}$ and spinal cord injuries. ${ }^{29}$ These findings are in agreement with our observations. Inspiratory muscle weakness limits inhalation of large air volumes during the inspiratory cough phase. Diminished lung volumes, secondary to inspiratory muscle weakness, decrease elastic recoil and expiratory pressure, and thereby reduce expiratory flow. ${ }^{1}$ This is probably why $\mathrm{P}_{\text {Imax }}$ and FVC were selected as independent variables that relate to $\mathrm{CPF}$ and could predict reduced CPF in older adults.

However, chest and abdominal wall mobility and physical performance showed significant weak correlations with $\mathrm{CPF}$. These results partially supported our hypothesis. However, chest and abdominal wall mobility and physical performance likely affect $\mathrm{CPF}$ indirectly via their more direct effects on lung volumes and respiratory muscle strength. In addition, there were no significant associations between CPF and physical activity or sedentary behavior. Freitas et $\mathrm{al}^{12}$ showed that an active lifestyle, assessed by a self-report questionnaire, was associated with increased CPF. Similarly, we found a significant difference in locomotive moderate-to-vigorous physical activity between the subjects with reduced and the subjects with non-reduced CPF but not a significant association between this variable and $\mathrm{CPF}$. 
Table 4. Diagnostic Accuracy of $\mathrm{P}_{\text {Imax }}$ and FVC in Detecting Reduced CPF

\begin{tabular}{|c|c|c|c|c|c|c|c|}
\hline Parameter & Cutoff Value & $\begin{array}{c}\text { AUC } \\
(95 \% \mathrm{CI})\end{array}$ & $P^{*}$ & $\begin{array}{c}\% \text { Sensitivity } \\
(95 \% \mathrm{CI})\end{array}$ & $\begin{array}{c}\% \text { Specificity } \\
(95 \% \text { CI) }\end{array}$ & $\begin{array}{c}\% \mathrm{PPV} \\
(95 \% \mathrm{CI})\end{array}$ & $\begin{array}{c}\% \mathrm{NPV} \\
(95 \% \mathrm{CI})\end{array}$ \\
\hline $\mathrm{P}_{\text {Imax }}, \mathrm{cm} \mathrm{H}_{2} \mathrm{O}$ & 47 & $0.70(0.56-0.85)$ & .10 & $76(50-93)$ & $60(45-74)$ & $41(24-59)$ & 88 (72-97) \\
\hline FVC, L & 2.05 & $0.81(0.69-0.93)$ & ND & $82(57-96)$ & $75(60-86)$ & $54(33-73)$ & $92(79-98)$ \\
\hline \multicolumn{8}{|c|}{$\begin{array}{l}\text { * Comparison of AUC values of } \mathrm{P}_{\text {Imax }} \text { and FVC. } \\
\mathrm{P}_{\text {Imax }}=\text { maximum inspiratory pressure } \\
\mathrm{AUC}=\text { area under the curve } \\
\mathrm{PPV}=\text { positive predictive value } \\
\mathrm{NPV}=\text { negative predictive value } \\
\mathrm{ND}=\text { no data }\end{array}$} \\
\hline
\end{tabular}

This discrepancy might have resulted from different assessment methods. That is, in older adults, self-report questionnaires tend to overestimate physical activity due to recall bias. To our knowledge, the results regarding the relationship between CPF and physical activity and sedentary behavior were previously unreported. Analysis of these results indicated that physical activity and sedentary behavior were unlikely to be independently associated with CPF in older adults. In a study that showed evidence of a significant relationship between locomotive moderate-tovigorous physical activity and physical performance in older adults, the significant difference in locomotive moderate-to-vigorous physical activity between the subjects with reduced and those with non-reduced CPF might relate to their respective physical performance. ${ }^{30}$

The present study found that $26 \%$ of the subjects had reduced CPF. Our study indicated that 16\% (23/120) (of the males, $12 \%$ [5/43]; and of the females, $23 \%$ [18/77]) of older adults without air-flow limitation exhibited CPF of $<240 \mathrm{~L} / \mathrm{min} .{ }^{14}$ Identifying the prevalence of reduced $\mathrm{CPF}$ in older adults was beyond the scope of this study. However, these findings indicate that older adults, particularly older females, are at increased risk of diminished cough function and increased risk of aspiration pneumonia when dysphagia exists as a concomitant condition. In our previous investigation, more adults with reduced CPF $(20.7 \%)$ than without reduced CPF (4.2\%) exhibited impaired swallowing function (eg, swallowing disorder or dysphagia). ${ }^{14}$ Therefore, CPF measures may help older adults understand their respiratory status and promote efforts to improve voluntary cough function.

We did not assess reflex cough function; however, Kulnik et $\mathrm{al}^{31}$ reported that the CPF of a voluntary cough, not a reflex cough, was significantly associated with a risk of pneumonia in subjects with acute stroke and dysphagia. In addition, the amount of time spent in sedentary behavior might have been underestimated due to the limited assessment period ( $\geq 4 \mathrm{~d}$ ), ${ }^{32}$ although physical activity was assessed by using an objective method according to previous studies. ${ }^{33,34}$ Furthermore, it is possible that our findings, obtained from a sample cohort, may not readily generalize to other community-dwelling older adults, although we estimated our sample size based on previous results. Also, the cross-sectional design of this study limited causal inferences regarding the observed associations. Further longitudinal and well-powered studies are needed to identify the causal relationship between CPF and its related variables in older adults.

\section{Conclusions}

FVC and $\mathrm{P}_{\text {Imax }}$ were independently associated with CPF, and FVC had a good sensitivity for detecting the reduced CPF in ambulatory community-dwelling older adults without air-flow limitation. Results indicate that lung volume and inspiratory muscle strength likely relate to cough strength and may help inform strategies for preserving and improving cough strength in older adults.

\section{REFERENCES}

1. McCool FD. Global physiology and pathophysiology of cough: ACCP evidence-based clinical practice guidelines. Chest 2006;129(1 Suppl): 48S-53S

2. Ebihara S, Sekiya H, Miyagi M, Ebihara T, Okazaki T. Dysphagia, dystussia, and aspiration pneumonia in elderly people. J Thorac Dis 2016;8(3):632-639.

3. Bianchi C, Baiardi P, Khirani S, Cantarella G. Cough peak flow as a predictor of pulmonary morbidity in patients with dysphagia. Am J Phys Med Rehabil 2012;91(9):783-788.

4. Kaneko H, Suzuki A. Effect of chest and abdominal wall mobility and respiratory muscle strength on forced vital capacity in older adults. Respir Physiol Neurobiol 2017;246:47-52.

5. Janssens JP. Aging of the respiratory system: impact on pulmonary function tests and adaptation to exertion. Clin Chest Med 2005; 26(3):469-484, vi-vii.

6. Smith JA, Aliverti A, Quaranta M, McGuinness K, Kelsall A, Earis J, Calverley PM. Chest wall dynamics during voluntary and induced cough in healthy volunteers. J Physiol 2012;590(3):563-574.

7. Buchman AS, Wilson RS, Boyle PA, Tang Y, Fleischman DA, Bennett DA. Physical activity and leg strength predict decline in mobility performance in older persons. J Am Geriatr Soc 2007;55(10):16181623.

8. Giua R, Pedone C, Scarlata S, Carrozzo I, Rossi FF, Valiani V, Incalzi RA. Relationship between respiratory muscle strength and 


\section{CPF AND Respiratory and Physical Parameters}

physical performance in elderly hospitalized patients. Rejuvenation Res 2014;17(4):366-371.

9. Summerhill EM, Angov N, Garber C, McCool FD. Respiratory muscle strength in the physically active elderly. Lung 2007;185(6):315320.

10. Burchfiel CM, Enright PL, Sharp DS, Chyou PH, Rodriguez BL, Curb JD. Factors associated with variations in pulmonary function among elderly Japanese-American men. Chest 1997;112(1):87-97.

11. Sillanpää E, Stenroth L, Bijlsma AY, Rantanen T, McPhee JS, MadenWilkinson TM, et al. Associations between muscle strength, spirometric pulmonary function and mobility in healthy older adults. Age (Dordr) 2014;36(4):9667.

12. Freitas FS, Ibiapina CC, Alvim CG, Britto RR, Parreira VF. Relationship between cough strength and functional level in elderly. Rev Bras Fisioter 2010;14(6):470-476.

13. Dyrstad SM, Hansen BH, Holme IM, Anderssen SA. Comparison of self-reported versus accelerometer-measured physical activity. Med Sci Sports Exerc 2014;46(1):99-106.

14. Suzuki A, Kaneko H. [Relationship between voluntary cough intensity and the respiratory, physical, oral and swallowing functions of the community-dwelling elderly]. Rigakuryoho Kagaku 2017;32(4): 521-525.

15. Miller MR, Hankinson J, Brusasco V, Burgos F, Casaburi R, Coates A, et al.; ATS/ERS Task Force. Standardisation of spirometry. Eur Respir J 2005;26(2):319-338.

16. Kubota M, Kobayashi H, Quanjer PH, Omori H, Tatsumi K, Kanazawa $M$. Reference values for spirometry, including vital capacity, in Japanese adults calculated with the LMS method and compared with previous values. Respir Investig 2014;52(4):242-250.

17. American Thoracic Society/European Respiratory Society. ATS/ERS Statement on respiratory muscle testing. Am J Respir Crit Care Med 2002;166(4):518-624.

18. Kaneko H, Shiranita S, Horie J, Hayashi S. Reduced chest and abdominal wall mobility and their relationship to lung function, respiratory muscle strength, and exercise tolerance in subjects with COPD. Respir Care 2016;61(11):1472-1480.

19. Podsiadlo D, Richardson S. The timed "Up \& Go": a test of basic functional mobility for frail elderly persons. J Am Geriatr Soc 1991; 39(2):142-148.

20. Jones CJ, Rikli RE, Beam WC. A 30-s chair-stand test as a measure of lower body strength in community-residing older adults. Res Q Exerc Sport 1999;70(2):113-119.

21. Ohkawara K, Oshima Y, Hikihara Y, Ishikawa-Takata K, Tabata I, Tanaka S. Real-time estimation of daily physical activity intensity by a triaxial accelerometer and a gravity-removal classification algorithm. Br J Nutr 2011;105(11):1681-1691.

22. DeLong ER, DeLong DM, Clarke-Pearson DL. Comparing the areas under two or more correlated receiver operating characteristic curves: a nonparametric approach. Biometrics 1988;44(3):837-845.

23. Gauld LM, Boynton A. Relationship between peak cough flow and spirometry in Duchenne muscular dystrophy. Pediatr Pulmonol 2005; 39(5):457-460

24. LoMauro A, Romei M, D'Angelo MG, Aliverti A. Determinants of cough efficiency in Duchenne muscular dystrophy. Pediatr Pulmonol 2014;49(4):357-365.

25. Park JH, Kang SW, Lee SC, Choi WA, Kim DH. How respiratory muscle strength correlates with cough capacity in patients with respiratory muscle weakness. Yonsei Med J 2010;51(3):392-397.

26. Szeinberg A, Tabachnik E, Rashed N, McLaughlin FJ, England S, Bryan CA, Levison H. Cough capacity in patients with muscular dystrophy. Chest 1988;94(6):1232-1235.

27. Arora NS, Gal TJ. Cough dynamics during progressive expiratory muscle weakness in healthy curarized subjects. J Appl Physiol Respir Environ Exerc Physiol 1981;51(2):494-498.

28. Tzani P, Chiesa S, Aiello M, Scarascia A, Catellani C, Elia D, et al. The value of cough peak flow in the assessment of cough efficacy in neuromuscular patients. A cross sectional study. Eur J Phys Rehabil Med 2014;50(4):427-432.

29. Postma K, Vlemmix LY, Haisma JA, de Groot S, Sluis TA, Stam HJ, Bussmann JB. Longitudinal association between respiratory muscle strength and cough capacity in persons with spinal cord injury: an explorative analysis of data from a randomized controlled trial. J Rehabil Med 2015;47(8):722-726.

30. Reid N, Daly RM, Winkler EA, Gardiner PA, Eakin EG, Owen N, et al. Associations of monitor-assessed activity with performance-based physical function. PLoS One 2016;11(4):e0153398.

31. Kulnik ST, Birring SS, Hodsoll J, Moxham J, Rafferty GF, Kalra L. Higher cough flow is associated with lower risk of pneumonia in acute stroke. Thorax 2016;71(5):474-475.

32. Matthews CE, Ainsworth BE, Thompson RW, Bassett DR Jr. Sources of variance in daily physical activity levels as measured by an accelerometer. Med Sci Sports Exerc 2002;34(8):1376-1381.

33. Hansen BH, Kolle E, Dyrstad SM, Holme I, Anderssen SA. Accelerometer-determined physical activity in adults and older people. Med Sci Sports Exerc 2012;44(2):266-272.

34. Trost SG, McIver KL, Pate RR. Conducting accelerometer-based activity assessments in field-based research. Med Sci Sports Exerc 2005;37(11 Suppl):S531-S543. 